Acta Technologica Agriculturae 1

Nitra, Slovaca Universitas Agriculturae Nitriae, 2021, pp. 14-19

\title{
STUDYING THE EFFECT OF BALANCER ON ENGINE VIBRATION OF MASSEY FERGUSON 285 TRACTOR
}

\author{
Niusha FARROKHI ZANGANEH, Gholamhossein SHAHGHOLI*, Soleiman AGH \\ University of Mohaghegh Ardabili, Ardabil, Iran
}

\begin{abstract}
The mechanical vibration causes health issues to drivers, such as backache, spinal cord injury, etc. In this regard, a tractor engine plays important role. Tractors without chassis are equipped with a balancer unit reducing the secondary engine vibrating force and decreasing the engine and tractor vibration. The paper presented investigates the effects of balancer on secondary vibration. In this research, the root mean square (RMS) of vibration was computed for specific periods of engine work. Effects of rotational speed and engine load on engine vibration in two modes with and without balancer were investigated. The results showed that, at full engine load, increasing the engine speed resulted in increasing the vibration in both observed modes. Balancer utilization reduced the vibration by $22.3 \%$ on average. At fixed rotational speed, increasing load caused an increase in vibration in both observed modes. At $1400 \mathrm{rpm}$ rotational speed and $125 \mathrm{Nm}$ torque, balancer utilization managed to reduce the RMS of secondary vibration by $38.9 \%$. Furthermore, at $250 \mathrm{Nm}$, RMS vibrations were reduced by $21.3 \%$ in comparison to no balancer mode. At full load, variable rotational speed, the balancer significantly reduced vibration by $29 \%$ on average. The balancer proved to be more efficient at lower torques.
\end{abstract}

Keywords: vibration; load; rotational speed; root mean square

As the most important agricultural machinery, tractor plays a main role in planting and harvesting operations and especially in mechanized agriculture. One of the most frequently used tractors in Iran is Massey Ferguson 285 (MF285) produced by Iranian Tractor Company, which is the biggest manufacturing factory in Iran and Middle East.

One of the factors reducing mental and physical health is vibration (Bellman, 2002). Vibration is investigated by a wide range of engineering sciences and studied in different aspects (Bulgakov et al., 2017). Tractors and agricultural implements are used for conducting field operations and the fatigue and discomfort are not the only results of physical work; moreover, these can be caused by exposure to vibration (Taghizadeh et al., 2007).

Apart from the side effects of vibration in terms of health risks to entire body, this phenomenon has also negative mental effects. The operators working under influence of vibration tend to retire earlier than expected and if they continue to work under such conditions, health risk probability increases during their work. A tired operator is less efficient and imposes higher costs to employer. On the other hand, for the employer, paying the disability insurance is one of the other side losses caused by vibration. Therefore, reducing the vibration resulting from operation of mechanical tools and its side effects on human body is necessary as one of the characteristics of evaluating devices. The vibration, however, does not show any destructive effects on human organs in short-term and only reduces the human efficiency (Babakhani et al., 2010). It causes numerous side complications in the long term to the operators who are daily exposed to vibration of high domain. The threshold of complications resulting from vibration varies for different people and depends on factors such as exposure time, vibration domain, frequency, etc. Therefore, it is impossible to define a specific threshold point for a specific person, however, the Society of Automobile Engineers (SAE), International Standard Organization (ISO) and British Standard (BS) defined a series of thresholds. It has been shown that the tractor vibration under different operation conditions usually exceeds the defined thresholds of ISO2631-1 (2018). Accordingly, exposure to tillage operation conditions should not exceed 2.5 hours. High domain and low frequency vibration are factors constituting physical health risks to operator in the long term (Babakhani et al., 2010). The vibration side effects to entire body occur when the working time exceeds the defined working times (ISO2631-1, 2018).

The main source of vibration in agricultural tractors is the engine. Engine vibration results from cylinder firing, impacts due to piston clearances (piston slaps), fuel injection pressure, high rise of gas pressure during combustion and the impacts of admission and exhaust valves (Carlucci et al., 2006). Moreover, considering the tractor vibration, there is a direct relation to its engine, which transfers the vibration to operator's seat. Therefore, the effects of each engine part on its overall function and vibration should be studied in detail. Therefore, recognition, studying and optimization of different parts related to establishing and propagation of vibration are very important. The engine is balanced if the forces on supports are constant under ordinary engine 
work conditions in terms of quantity and their direction. In unbalanced engine, the pressure at supports varies frequently, causing engine vibration, which ultimately leads to vibration of the entire vehicle (Juan et al., 2017).

Vibration occurs in engines due to three main reasons (manufacturers consider these in designing and balancing the engine in order to reduce the vibration):

- vibration due to unbalance of rotatory parts: there is centrifugal force in each rotating part such as crankshaft, flywheel and clutch;

- vibration due to piston impact during crankshaft rotation (the crankshaft does not rotate at uniform speed because of external impacts), which can cause rotating vibration;

- vibration due to inertia of reciprocating parts - it occurs mostly due to piston's inertia especially in lower and upper parts of cylinder, where piston tends to continue motion; when piston reaches the TDS (top dead centre) and BDC (bottom dead centre), an inertia force produced engine vibration. This depends on increasing the engine speed (Breeze, 2018).

Gas pressure of combustion creates two force components, which is the main reason for engine vibration. There are two important factors for vibration production in internal combustion engines. The first factor is related to unbalance of torque and forces due to circulating or reciprocal movement of crankshaft and its parts. These issues can be balanced in six-cylinder engines or higher. In engines with less than six cylinders, there is always resistance or coupling force, which cannot be removed via balancing. The primary vibration established by these imbalances occurs at frequency uniform with engine speed and it is called first rank vibration. Vibration harmonics (also called second rank/third rank vibration) occur two or three times per engine rotation frequency. Due to the number of cylinders and arrangement of cranks, the resistance forces are retrofitted or removed upon changing the angle and it has lesser vibration domain. The second source of engine vibration produced by torque pulses results from increasing the gas pressure in combustion (Taghizadeh, 2011).

The weights are used for neutralizing the rotational inertia force. Bush bearings of shafts are lubricated by pressure, and the roller bearings of pump actuator shaft and idle gear are lubricated by spraying. Oil pump, balancer and pressure breaker valve are integrated. Rotating force of crankshaft rotates the crankshaft gear connected to the idle gear of balancer. On the other hand, this gear is connected to gear of balancer shaft and rotates the balancer weight via connecting pin on the shaft. The weights are connected via gear to each other, and rotation of one leads to rotation of the other. These weights rotate opposite to each other to eliminate the vibration. At both ends of two shafts, there are two needle roller bearings. At the end of balancer shaft, there is an oil pump gear operating the oil pump. The rotational speed of balancer shaft is twice the engine rotational speed to remove the secondary vibrating force of four-cylinder engine. However, regarding the design of crankshaft, connecting rod, piston and engine speed, the value of vibrating force is not specified. The balancer synchronizes with crankshaft in a manner that, when the centrifugal weights reach the low death point, a pair of pistons are located at the top death point (Goering and Hansen, 2014). Without the balancer, there occurs tractor vibration due to unavailability of damper and direct connection of engine to chassis (MF285 tractor engine is part of tractor chassis).

Ettefagh et al. (2008) studied knocking in petrol engines upon vibrating, analysing the cylinder block, and presented a parametrical model; they modelled vibrating signal of cylinder block with ARMA (Auto Regressive Moving Average) parametrical model. Moving average (MA) parameters, which were estimated, are very sensitive to knocking. Having revealed such parameters, it may be possible that knocking appears in primary function stages in spark ignition engines. The results show that the proposed method can reveal knocking with low sampling frequency via a simple software, which reduces the computation time and software costs. In this research, a new method of synchronous tachometer pulses with accelerometer sensor is introduced for estimating the knock-sensitive window (KSW). Taghizadeh et al. (2007) simulated the vibration of six-cylinder diesel engine using mixtures of diesel fuel and biodiesel via neural network. The results showed that the vibration remarkably decreases after engine serving, the fuel mixture has significant effect on vibration: B20 and B40 mixtures showed the least vibration; the most vibration occurred using B15 and B30 mixtures. The results showed that the best topology for predicting the RMS is neural network with 40-30-30-1 structure with trainlm training algorithm and logsis, tansig and pureline threshold functions.

Guzzomi et al. (2007) proved that torsional vibration in engines show certain phenomena, which are not common about vibration. These effects result from reciprocal mechanism geometry and are revealed with dynamic and kinematic analyses. Moment of inertia varies with crankshaft rotating and the results showed that vibration is influenced by the friction between cylinder and piston.

The goals of this research are as follows:

1. determining the relationship between different engine speeds and balancer function on those speeds;

2. determining the relationship between different engine loads and balancer function under these loads;

3. studying the vibration of MF285 tractor engine with and without balancer.

\section{Material and methods}

Imbalance in rotating machines is one of the main factors of vibration. Simplified model of such devices is shown in Fig. 1. The entire device mass is $M$ and there are two centrifugal masses of $m / 2$, which rotate in opposite directions at constant angular velocity of $\omega$. Centrifugal force of $\frac{m e \omega^{2}}{2}$ causes device mass stimulation. Two equal masses $\mathrm{m} / 2$ rotating in opposite directions are chosen from this direction and horizontal stimulation components are gathered and neutralize each other. However, vertical stimulation components are gathered and act along A-A axis in Fig. 1. 
The total acting force of components along the vertical axis was calculated as follows:

$$
F(t)=\operatorname{me} \omega^{2} \sin \omega t
$$

where:

$$
\begin{array}{cc}
\omega \quad \text { - } & \text { rotation velocity of balancing } \\
& \text { masses, rad. } \mathrm{s}^{-1} \\
e \quad- & \text { mass rotation radius, } \mathrm{m}
\end{array}
$$

Tractors without chassis are equipped with a balancer unit (Fig. $2)$, which is installed in carter and moves via timing gears located in engine front. Fig. 2 shows that the balancer is composed of balancer shell, balancer weights, idle gear, spiral gear, spur gears of balancer weights, and balancer shaft. Balancer weights were installed on the shafts.

Single differential MF-285 tractor produced by Iran Tractor Company was used in this research. Table 1

\begin{tabular}{|c|c|}
\hline $\begin{array}{l}\text { Made by Iran, Motorsazan Co., } \\
\text { MTI440C-105AD Model }\end{array}$ & Weight: 380 kg \\
\hline $\begin{array}{l}\text { type of diesel Direct spraying: } \\
\text { Number of cylinders: } 4: 4 \\
\text { Compression ratio: } 17.5: 1 \\
\text { Cylinder diameter: } 100 \mathrm{~mm} \\
\text { Piston course: } 127 \mathrm{~mm} \\
\text { Volumetric capacity: } 3.99 \mathrm{~L}\end{array}$ & $\begin{array}{l}\text { General dimensions } \\
\text { Length: } 720 \mathrm{~mm} \\
\text { Width: } 550 \mathrm{~mm} \\
\text { Height: } 980 \mathrm{~mm}\end{array}$ \\
\hline \multirow[t]{2}{*}{$\begin{array}{l}\text { Standard of pollution limitation } \\
\text { ECE-R96-Stage } 2 \\
\text { ECE-R24 }\end{array}$} & $\begin{array}{l}\text { Air inlet system: turbo charge and air to air cooler } \\
\text { Rotation direction: clockwise in front side } \\
\text { Cooling system: via water and equipped with oil } \\
\text { cooling } \\
\text { Electrical system: } 24 \text { Volt }\end{array}$ \\
\hline & $\begin{array}{l}\text { Maximum power: } 78 \mathrm{KW} \text { in } 2200 \mathrm{rpm} \\
\text { Maximum torque: } 375 \mathrm{NM} \text { in } 1400 \mathrm{rpm}\end{array}$ \\
\hline
\end{tabular}
displays the tractor technical details. This research utilizes a four-cylinder
Table 1 Technical details of engine in MF-285 tractor

and four-stroke engine made by Motorsazan Company.

In order to measure the torque (load), eddy-current dynamometer (E400 model) by Pouya microtools industries development company with capacity of $7000 \mathrm{rpm}$; the maximum torque of $400 \mathrm{Nm}$; and the maximum power of $150 \mathrm{hp}$ was used and connected to flywheel. For the purposes of collecting the engine vibration signals, vibrometer equipped with piezoelectric sensor (Model AC102-1A) made by VMI factory was used (Fig. 3); this device comes with accuracy of $100 \mathrm{mv} \cdot \mathrm{g}^{-1}$ and sensitivity

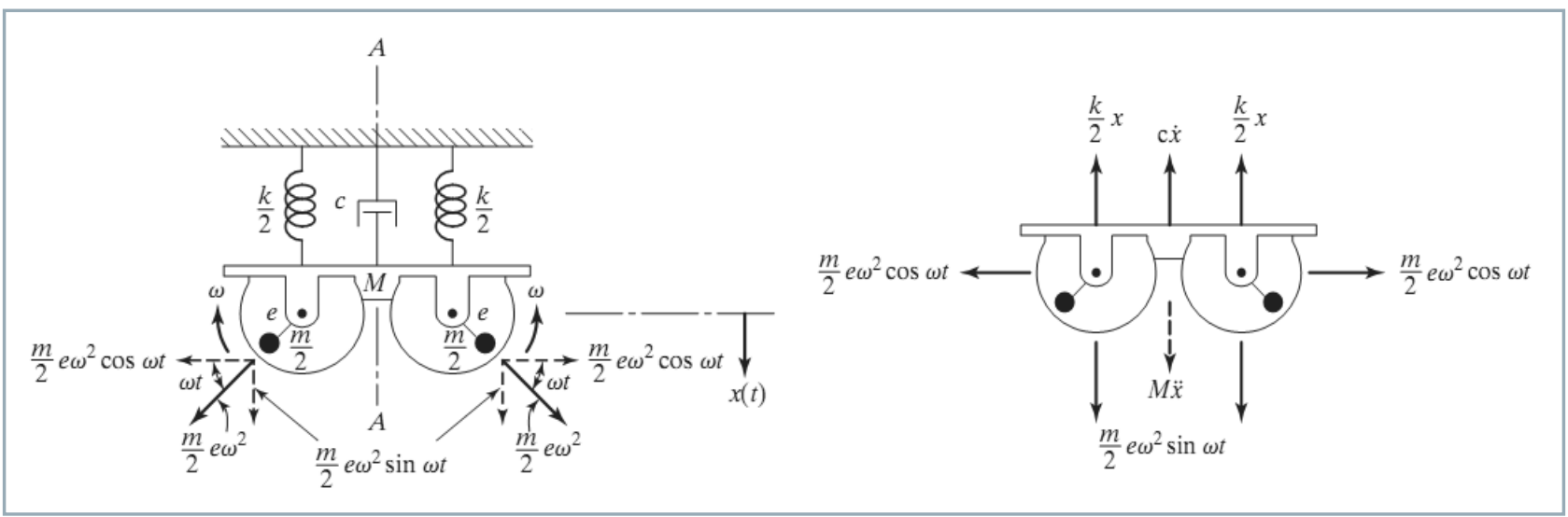

Fig. 1 Total acting forces on rotating unbalanced masses (top) and acting forces in horizontal and vertical directions (bottom)

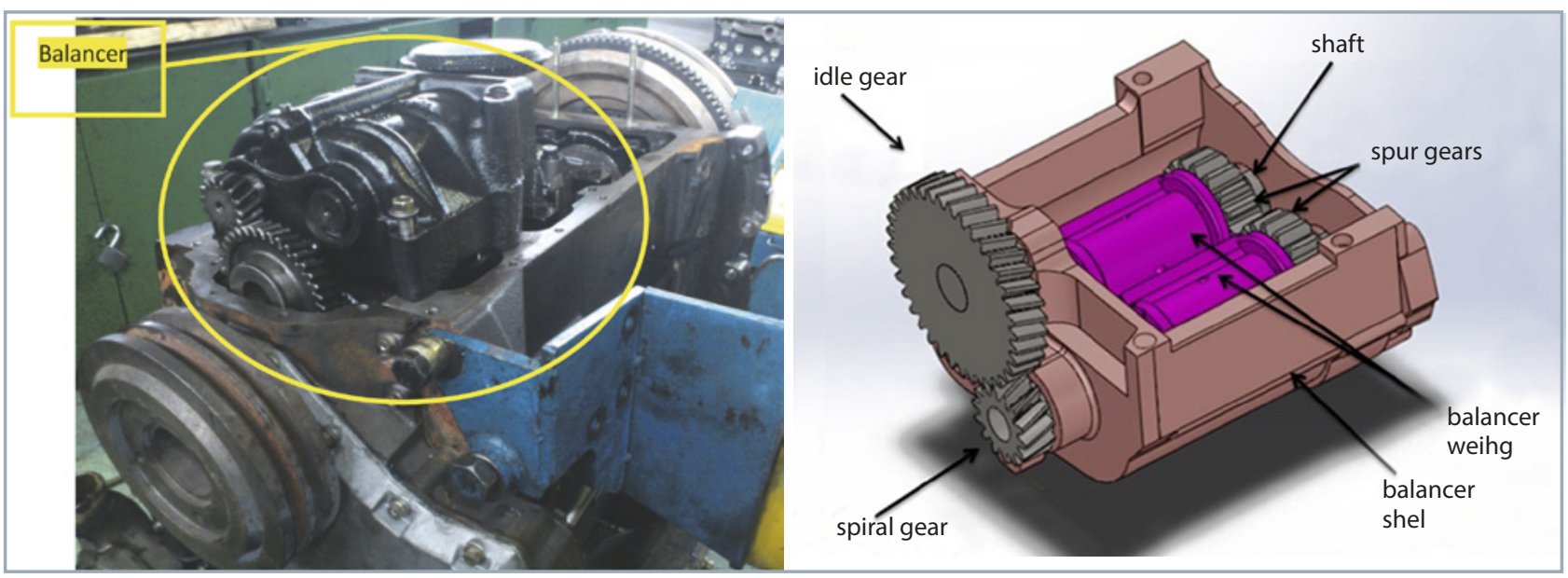

Fig. 2 Balancer unit location in MF-285 tractor engine (left); View of balancer with its composing parts (right) 


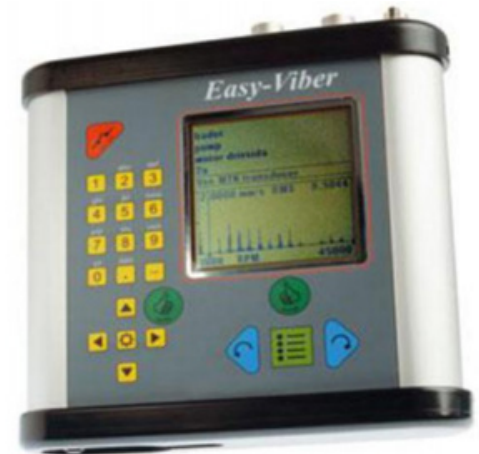

(a)

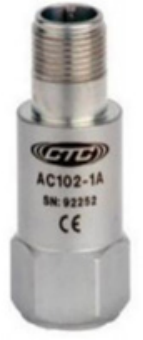

(b)
Fig. 3 a) Vibrometer device; b) Vibrometer sensor

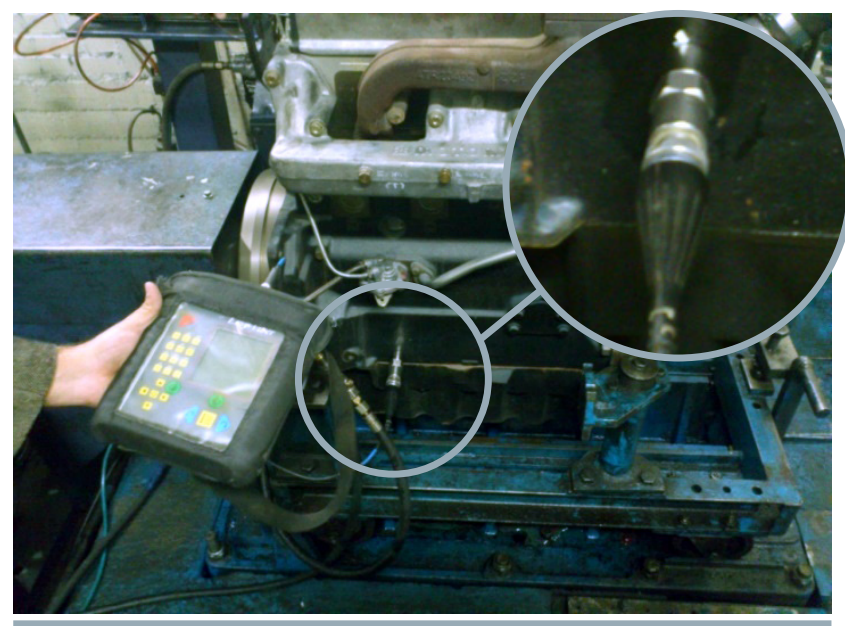

Fig. 4 Vibrometer connection to engine

of $\pm 10 \%$ and it can measure frequencies ranges from 0.5 to $15000 \mathrm{~Hz}$. Its main advantages include that it has no compression, and high frequency domain and precision (Ahirrao et al., 2018).

The vibrometer connection was performed magnetically - there is no loosing between vibrometer and engine body, and the connecting place was fully clear. The connecting place of vibrometer to cylinder lies in fixed crankshaft bearing on flywheel side (ISO 8528-9, 2017), located $17 \mathrm{~cm}$ from cylinder side and $9 \mathrm{~cm}$ from cylinder floor in engine (Fig. 4). Calibration was performed according to the manufacturer's calibration certification, inserting relevant coefficients in the software.

Experiments were conducted at Motorsazan Company of Tabriz. Tractor engine was inside test cell platform under controlled conditions (Fig. 5). The engine studied was tested in full-load mode (mode in which the vehicle uses majority of power or torque of engine; it is like the vehicle would be going uphill) and no-load mode (no power is taken from engine, which means that the vehicle is either in neutral state or is going downhill). Firstly, in no-load mode, the vibration value was measured at engine speeds of 750 and 2400 rpm; subsequently, in full-load mode, the vibration value was measured at rotational speeds of 1400 and 2200 rpm. Finally, at a constant engine speed of $1400 \mathrm{rpm}$, the load on engine was decreased to half value, in order to compare the results of engine vibration with and without

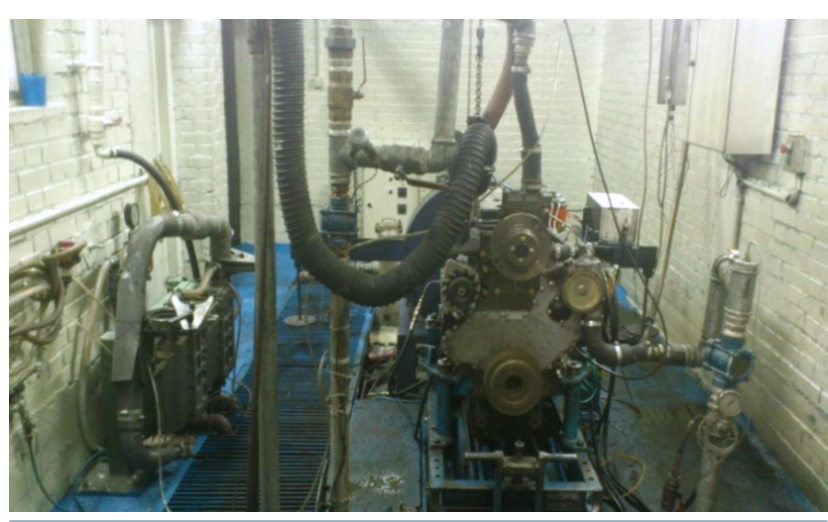

Fig. 5 Test cell used for conducting experiments at Tabriz Motorsazan Company

balancer. The experiments mentioned were conducted for both modes with and without balancer. According to the claims of Tabriz Motorsazan Company, these modes have critical points allocating more vibration than other modes.

In order to express the RMS (root mean square) value of engine vibration, it is possible to employ three vibration parameters: displacement signal, vibrating speed signal and vibrating acceleration signal (Taghizadeh, 2011). For the purposes of analysis, the output signal RMS value of speed was obtained and used to investigate the engine vibration $\left(\mathrm{mm} \cdot \mathrm{s}^{-1}\right)$. The RMS value of vibration was calculated as follows:

$$
a_{R M S}=\sqrt{\frac{1}{n} \sum_{i=1}^{N} a_{i}^{2}}
$$

where:

$a_{\text {RMS }}$ - root mean square of vibration values, $\mathrm{mm} \cdot \mathrm{s}^{-1}$

$a^{-}$- vibrating data, $\mathrm{mm} \cdot \mathrm{s}^{-1}$

$N \quad$ - total number of vibration data

\section{Results and discussion}

For all modes, vibration data were recorded, and all graphs were extracted. Fig. 6 shows a sample of the results of vibrating speed signal of engine at $1400 \mathrm{rpm}$ and load of $125 \mathrm{Nm}$.

\section{Laboratory results of balancer performance in different speeds with no load}

Fig. 7 shows the engine operation in two modes with and without balancer at $750 \mathrm{rpm}$ and $2400 \mathrm{rpm}$, and no load. In no-load mode and at $750 \mathrm{rpm}$, the balancer reduced the RMS of secondary vibration by $40.4 \%$; at $2400 \mathrm{rpm}$ and no load, it reduced the RMS value by up to $12.733 \%$. Therefore, using balancer in no-load mode is more effective at lower speeds. In general, balancer helped to reduce the vibration by $28.8 \%$ on average. Kumhar et al. (2016) concluded that internal combustion engine on dynamics generates the first-order and second-order inertial forces depending upon the configuration. These are transmitted through the engine to vehicles' structure and finally to the driver compartment and cause discomfort. The secondary inertial forces from 


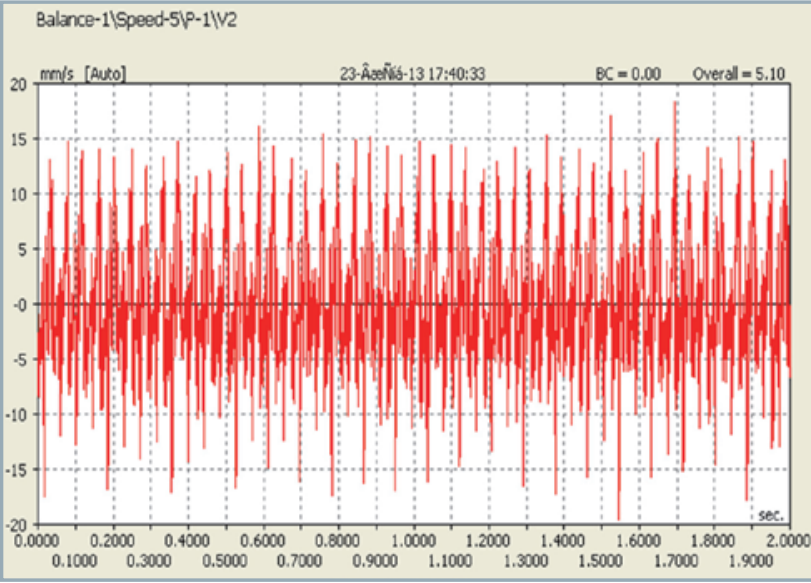

Fig. 6 Vibrating speed (vertical axis) signal in experiment vs time (horizontal axis) at rotational speed of $1400 \mathrm{rpm}$ and load of $125 \mathrm{Nm}$

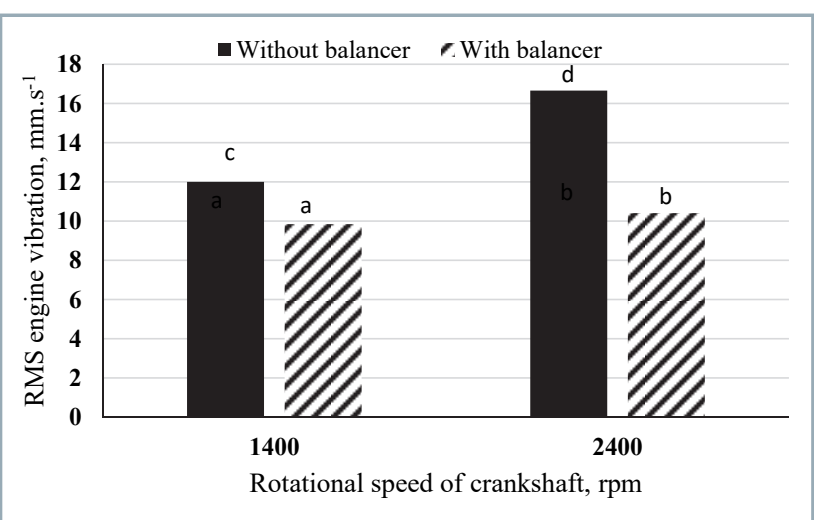

Fig. 7 Balancer effect on decreasing engine vibration at two engine speeds (750 and $2400 \mathrm{rpm}$ ) without load different alphabets of $a, b, c, d$ show significant difference between treatments

in-line four-cylinder engine cause the vibration, which can be attenuated by installing the twin secondary balancer shaft rotating in opposite directions at twice the speed of crankshaft. Utilizing balancer at 2200 rpm, Kumhar et al. (2016) observed vibration reduction by $95 \%$; at lower speed/ high torque and high speed/low torque conditions at 1400 rpm and $2750 \mathrm{rpm}$, the vibration decrements were $90.82 \%$ and $94.4 \%$, respectively. Gravalos et al. (2014) measured two types of tractor acceleration using the PSV-400 scanning laser vibrometer (Polytec) and the $4500 \mathrm{~A}$ piezoelectric accelerometer, observing that the fibre-reinforced plastic hood (Lamborghini R6) showed the maximum vibration levels at $800 \mathrm{rpm}$, while the average acceleration values were greatly diminished at speed values exceeding $1000 \mathrm{rpm}$. The steel sheet hood of Renault 361 tractor showed similar vibration behaviour. Furthermore, Freydooni et al. (2012) came to similar results as previous authors - the minimum value of tractor vibration occurred at engine rotational speed of 1300-1400 rpm; after exceeding these values, the vibration increased proportionally to engine speed.

\section{Laboratory results of balancer function at different loads (125 and $250 \mathrm{Nm}$ ) and constant speed (1400 rpm)}

Fig. 8 shows the engine operation in two modes - with and without balancer - and at torques of 250 and $125 \mathrm{Nm}$, and constant rotational speed of $1400 \mathrm{rpm}$. Fig. 8 indicates that increasing the load resulted in increased engine vibration. In this case, balancer utilization at $1400 \mathrm{rpm}$ rotational speed and $125 \mathrm{Nm}$ torque helped to reduce the RMS of secondary vibration by $38.9 \%$. Meanwhile, RMS vibration reduction at $250 \mathrm{Nm}$ was by $21.3 \%$ in comparison to no balancer mode. Therefore, using balancer at lower torque values was more effective for vibration reduction. Generally, in this mode, balancer helped to reduce the vibration by $29.6 \%$ on average. The vibration increment with increase in the engine load can be caused by increasing the intensity and pressure of combustion inside the cylinder, which results from more intense fuel spraying to combustion chamber and more significant piston impacts.

\section{Balancer effects on engine RMS vibration at full load and different rotational speeds}

Fig. 9 presents the engine vibration in two modes (with and without balancer) at full load of $250 \mathrm{Nm}$, and rotational

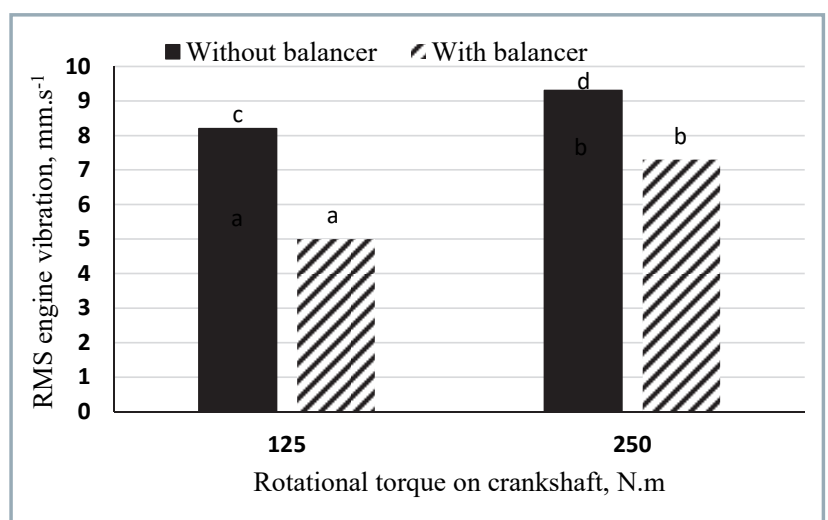

Fig. 8 Balancer function at different loads and rotational speed of $1400 \mathrm{rpm}$ - different alphabets of a, b, c, d show significant difference between treatments

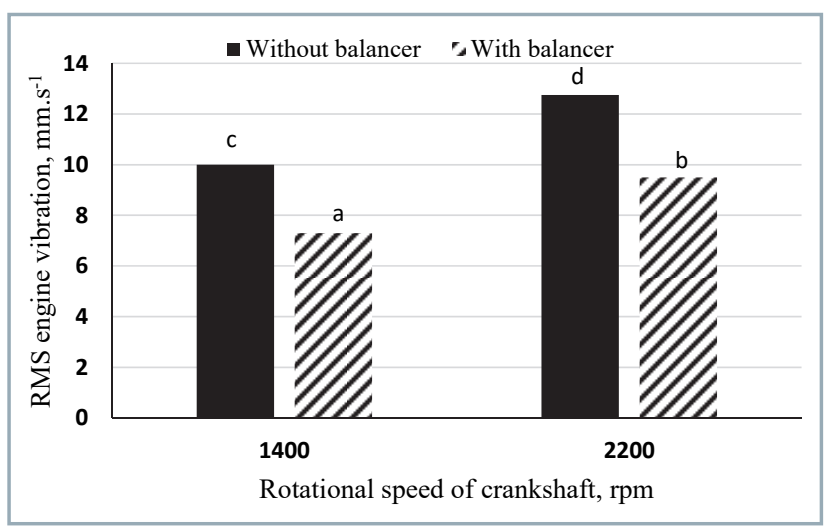

Fig. 9 Balancer effects on decreasing the vibration at full load $(250 \mathrm{Nm})$ at two rotational speeds (2200 and 1400 rpm) - different alphabets of a, b, c, d show significant difference between treatments 
speeds of $1400 \mathrm{rpm}$ and $2200 \mathrm{rpm}$. As it can be seen, increasing the rotational speed from 1400 to $2200 \mathrm{rpm}$ increased the vibration in both modes - with and without balancer. Balancer utilization at full load helped to decrease the RMS of secondary vibration by $21.3 \%$ at $1400 \mathrm{rpm}$. At $2200 \mathrm{rpm}$, the decrement was $23.1 \%$. Generally, in this mode, balancer utilization helped to reduce the vibration by $22.3 \%$ on average, and it was found that, in full-load mode, the balancer was more efficient at higher rotational speeds.

According to Fig. 9, in full-load mode, increasing the engine speed increased the RMS vibration of engine. Taghizadeh (2011) observed similar results in this area. Increase in vibration occurring while increasing the speed can be due to higher intensity and pressure of combustion inside the cylinder; in order to increase the engine speed, more fuel is sprayed to combustion chamber, resulting in increased combustion energy that inducts more force to engine body, which leads to amplifying of engine body vibration.

\section{Conclusion}

- In terms of no-load mode, balancer utilization significantly helped to reduce the vibration in contrast to mode without balancer. Increasing the rotational speed caused the engine vibration to increase as well. Balancer utilization in no-load mode was more efficient at lower speeds. Generally, results showed that balancer is capable of vibration reduction by $28.8 \%$ in no-load mode.

- In terms of full-load mode, increasing the rotational speed resulted in increment in vibration in both modes with and without balancer. Generally, balancer helped to reduce the vibration by $22.3 \%$. Results showed that the balancer was more efficient at high rotational speeds in full-load mode.

- At rotational speed of $1400 \mathrm{rpm}$, increasing the load from 125 to $250 \mathrm{Nm}$ led to vibration increment in both modes with and without balancer. On average, balancer utilization helped to reduce the vibration by $29 \%$. Under such conditions, balancer is more efficient at lower torques.

\section{References}

AHIRRAO, N. S. - BHOSLE, S. P. - NEHETE, D. V. 2018. Dynamics and vibration measurements in engines. In Procedia Manufacturing, vol. 20, pp. 434-439.

BABAKHANI, N. G. - GHOBADIAN, B. - SALAHSHOOR, K. MOHTASEBI. S. 2010. Vibration suppression and safety seat motion design of a hyper active seat. In Journal of Vibro engineering, vol. 2, no. 1, pp. 57-66.

BELLMANN, M. A. 2002. Perception of Whole Body Vibration: From Basic Experiments to Effects of Seat and Steering Wheel Vibrations on Passenger's Comfort Inside Vehicles. PhD Thesis, University of Oldenburg, Germany.
BREEZE, P. 2018. Piston Engine-Based Power Plants, Academic Press. 102 pp. ISBN 9780128129043.

BULGAKOV, V. - ADAMCHUK, V. - NOZDROVICKÝ, L. - IHNATIEV, Y. 2017. Theory of vibrations of sugar beet leaf harvester frontmounted on universal tractor. In Acta Technologica Agriculturae, vol. 20, no. 4, pp. 96-103.

CARLUCCI, A. P. - CHIARA, F. F. - LAFORGIA, D. 2006. Analysis of the relation between injection parameter variation and block vibration of an internal combustion diesel engine. In Journal of Sound and Vibration, vol. 295, no. 1-2, pp. 141-164.

ETTEFAGH, M. M. - SADEGHI, M. H. - PIROUZPANAH, V. - ARJMANDITASH, H. 2008. Knock detection in spark ignition engines by vibration analysis of cylinder block: A parametric modeling approach. In Mechanical Systems and Signal Processing, vol, 22, pp. $1495-1514$

FREYDOONI, M. - LORESTANI, A. N. - RABBANI, H. - JAVADIKIA, P. 2012. Measurement and analysis of vibration of operator in Universal 650, Massey Ferguson 285 \& MF 299 Tractors. In International Journal of Mechanics and Applications, vol. 2, no. 5, pp. 88-92.

GOERING, C. E. - HANSEN, A. S. 2014. Engine power and tractor. American Society of Agricultural and Biological Engineers (ASABE), $4^{\text {th }}$ edition, St. Joseph, Michigan.

GRAVALOS, I. - LOUTRIDIS, S. - GIALAMAS, T. - AUGOUSTI, A. KATERIS, D. - XYRADAKIS, P. - TSIROPOULOS, Z. - LIBRA, M. 2014 Vibrational behavior of tractor engine hood. In Fine Mechanics and Optics, vol. 3, pp. 69-71

GUZZOMI, A. - HESTERMAN, D. - STONE, B. 2007. The effect of piston friction on the torsional natural frequency of a reciprocating engine. In Mechanical Systems and Signal, vol. 21, pp. 2833-2837.

ISO 8528-9. 2017. Reciprocating internal combustion engine driven alternating current generating sets - Part 9: Measurement and evaluation of mechanical vibrations.

ISO 2631-1. 2018. Mechanical vibration and shock - Evaluation of human exposure to whole-body vibration - Part 1: General requirements.

JUAN, X. - XUEHUI, Z. - JIANJUN, Z. - XUAN, L. 2017. Vibration characteristics of unbalance response for motorized spindle system. In Procedia Engineering, vol. 174, pp. 331-340.

KUMHAR, G. K. - SINGH, S. K. - BABHALE, T. 2016. Design and analysis of four cylinder diesel engine balancer shaft. In International Journal of Engineering Research \& Technology, vol. 5, no. 8, pp. 103-108.

TAGHIZADEH, A. - TAVAKOLI HASHCHIN JASHGIN, T. - GHOBADIAN B. 2007. Analyzing the daily exposure of user with two-wheel tractor vibrations. In Agricultural Engineering Researches Journal, vol. 8, no. 4, pp. 18-30.

TAGHIZADEH, A. 2011. Studying the Parameters of MF 399 Tractor Vibrations Signal via Diesel and Biodiesel Fuels. PhD dissertation, University of Tarbiat Modarres, Tehran. 